\title{
The class as a learning entity (complex adaptive system): An idea from complexity science and educational research
}

\author{
CRAIG NEWELL \\ Simon Fraser University
}

\begin{abstract}
Educational theorists are making increasing use of the metaphors and concepts of complexity thinking in their discourses. In particular, Professors Brent Davis, Elaine Simmt, and Dennis Sumara have written extensively about using complexity thinking to shift attention from the individual student as the locus of learning (cognizing agent) to the social collective — the class — as the locus of learning. In this model, the class (students and teacher) is (potentially) a complex adaptive system. The students and teacher remain complex adaptive systems in their own right, but through dynamic local interactions there is the possibility of emergent behaviours indicative of learning that transcends that of the individuals within the class. The social collective we know as a class becomes an instance of the Aristotlean adage, "The whole is greater than the sum of its parts." (With the coda that we cannot understand the whole by merely understanding the components.) Davis, Simmt, and Sumara have segued from complexity-informed descriptions of educational collectives to discussions about facilitating the self-organization of classes into complex adaptive systems - learning systems, in their language.

In this paper, I discuss complex adaptive systems and look at how Davis, Simmt, and Sumara developed their thesis that the class collective, rather than individual student, is the appropriate level to investigate learning and teaching. We conclude by addressing some of the possibilities and challenges inherent in such a redescription of communities of learners.
\end{abstract}

\section{Introduction}

Complexity science is a way of investigating and discussing a class of phenomena from many different disciplines that is resistant to being understood through reductionistic analysis. Davis noted that, "Unlike analytic science, complexity science is defined more in terms of its objects of study than its modes of investigation."1 Unsurprisingly these "objects of study" are identified as complex and have behaviours and traits that in some ways exceed the aggregate of the components. Aristotle proclaimed in his Metaphysics that the whole was greater than the sum of its parts; complexity science revitalizes this principle after centuries of understanding the universe as clockwork mechanisms. Associated with complex objects and phenomena are the incompletely understood and possibly equivalent attributes of emergence and self-organization.

\footnotetext{
${ }^{1}$ Brent Davis, Inventions of Teaching: A Genealogy (Mawah, NJ: Lawrence Erlbaum,2004), 150.

(C) Copyright 2008. The author, Craig Newell, assigns to the SFU Educational Review the right of first publication and educational and non-profit institutions a non-exclusive license to use this document for personal use and in courses of instruction provided that the article is used in full and this copyright statement is reproduced. Any other usage is probibited without the express permission of the author.
} 
Complexity science has historical antecedents stretching back to the beginning of the twentieth century, ${ }^{2}$ but has begun to have its own identity as a field of inquiry since the mid-1980's. ${ }^{3}$ The use of complexity thinking in education research discourses is even more recent. ${ }^{4}$ Not even the most ardent adherents of complexity science would say that complexity science has achieved maturity in the Kuhnian sense. Complexity science in general and its applications to education in particular continue to be very much works in progress. As such there is the excitement of new ideas, images, and language being introduced into the conversation, but there is also the indeterminacy and ambivalence associated with a field of study that has not yet coalesced into coherent theory.

In this paper, I present an example of how complexity science has been used in educational research, beginning with an examination of the nature of complex adaptive systems and continuing with the argument that such systems can be thought of as learning systems. These learning systems may be comprised of human beings and, in particular, a class of students and teacher(s) may cohere into such an entity. Three Canadian researchers, Brent Davis, Elaine Simmt, and Dennis Sumara, present the thesis that it might be fruitful to investigate the classroom collective as the locus of learning in schools, rather than the individual student. I outline their work and discuss the advantages and challenges that might ensue.

\title{
Complex adaptive systems
}

Complexity science begins with distinguishing between the complex and the complicated. Warren Weaver is credited with first making this distinction in a 1948 paper. ${ }^{5}$ Davis and Sumara outline the difference as follows.

\begin{abstract}
...although a complicated system might have many components, the relationship among those parts is fixed and clearly defined. If it were carefully dismantled and reassembled, the system would work in exactly the same way. However, there exist some forms that cannot be dismantled and reassembled, whose characters are destroyed when the relationships among components are broken. Within these sorts of complex systems, interactions of components are not fixed and clearly defined, but are subject to on-going co-adaptations. ${ }^{6}$
\end{abstract}

The iconic example of a complicated system is a clock; that of a complex system is a living organism. Complicated systems are mechanical. They obey the laws of (classical) physics. In particular, complicated systems are particularly mindful of the second law of thermodynamics-they run down. In contrast, complex systems seem to defy entropy and spontaneously generate order. Complex systems are better comprehended through the principles of biology and evolution. To the degree that physics is commonly regarded in its pre-relativistic and pre-quantum mechanical forms, and biology is

\footnotetext{
${ }^{2}$ See, e.g., Fritjof Capra, The Web of Life (New York: Doubleday, 1996).

${ }^{3}$ The Santa Fe Institute, began in 1984. The early history of the institute is chronicled in M. Michael Waldrop, Complexity: the emerging science on the edge of order and chaos (New York: Simon and Schuster, 1992). This may be one date to associate with the "beginning of complexity science."

${ }^{4}$ William Doll, Jr. began writing papers in the late 1980s invoking complexity science concepts in curriculum theory discourses. He brought many of these ideas together in William Doll, Jr., A post-modern perspective on curriculum (New York: Teachers' College Press, 1993), carrying them forward in Doll, W., Fleener; M. J. Trueit, D.; \& St. Julien, J. (Eds.), Chaos, complexity, curriculum, and culture: A conversation (New York, Peter Lang, 2005). The Chaos and Complexity Theory Special Interest Group of the American Education Research Association first met in 1996.

${ }^{5}$ Cf. Brent Davis and Dennis Sumara, Complexity and Education: Inquiries in Learning, Teaching, and Research (Mawah, NJ: Lawrence Erlbaum, 2006), 8-9.

${ }^{6}$ Ibid, p. 11.
} 
informed by post-Darwinian concepts of evolution, complex systems encourage a shift from physics to biology as the canonical science. ${ }^{7}$

Bateson $^{8}$ famously distinguished between the responses of living and inanimate systems by his thought experiment of comparing the outcomes when kicking a rock and kicking a dog. Physics will indeed help with approximating the rock's motion, but it is completely inadequate for either predicting or describing the dog's response. Prediction and control are better suited to complicated systems than to complex systems.

A defining characteristic of complex systems is emergence or self-organization. "For reasons that are not fully understood, under certain circumstances agents can spontaneously cohere in functional collectives - that is, they come into unities that have integrities and potentialities that are not represented by the individual agents." ${ }^{9}$ Emergence is manifest whenever we look at a flock of birds dancing in the sky or attempt to comprehend beehives or ant colonies. ${ }^{10}$

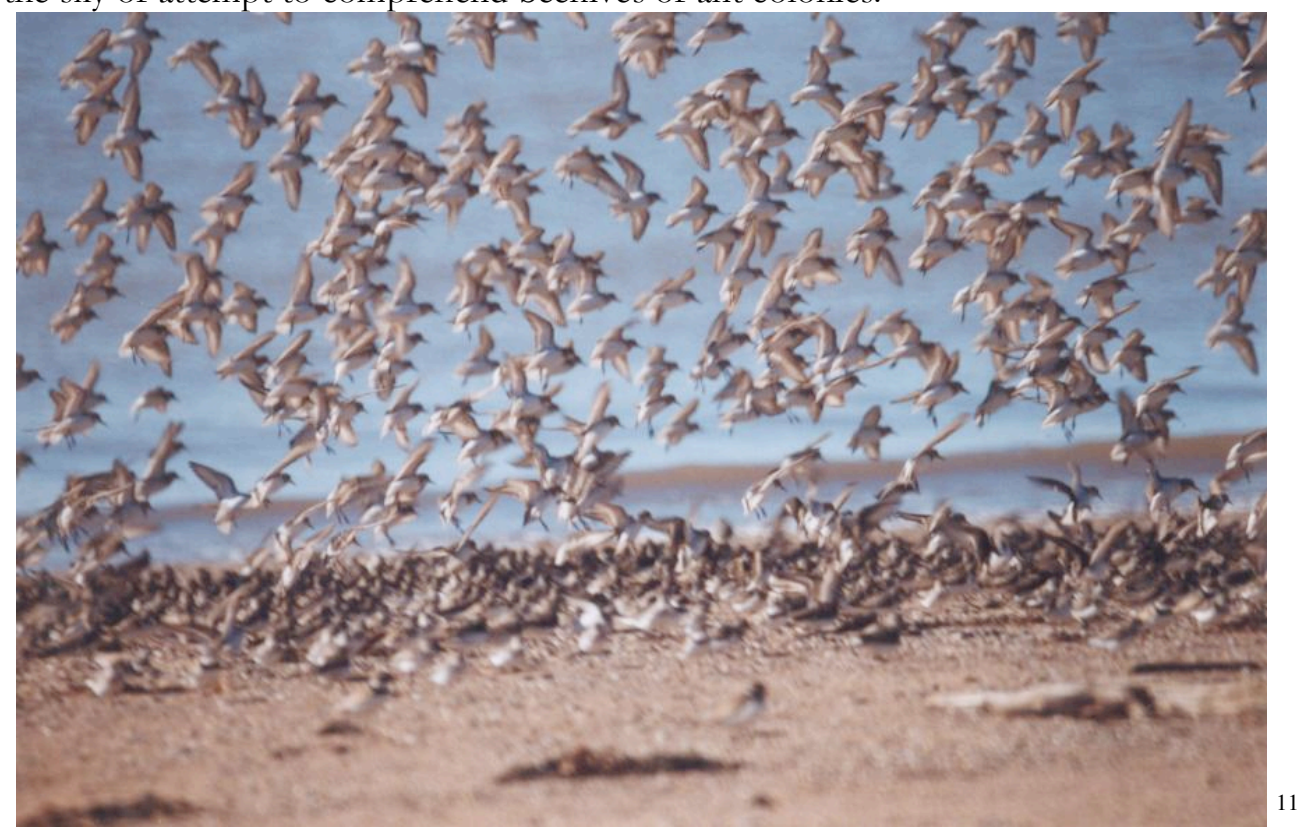

Complex systems are self-organizing and self-maintaining, but many also have the ability to adapt in changing environments. Complicated systems transfer and transmit energy and information; complex systems have the ability to transform. ${ }^{12}$ An example of a complex system adapting is how the ecology of the Great Lakes not only recovered from the introduction of an exotic species (zebra mussels) in the late 1970's but actually incorporated these mollusks into a new and improved ecology. The mussels,

\footnotetext{
${ }^{7}$ Cf. Doll, 1993 and Capra, 1996. The complicated/complex distinction is not simply one of separating the inanimate from the animate. Prigogine documented complex chemical reactions and modern genetics is a masterpiece of analytic, reductionist science.

${ }^{8}$ Gregory Bateson, Mind and Nature: A Necessary Unity (Cresskill,NJ: Hampton,1979).

${ }_{9}^{9}$ Brent Davis and Elaine Simmt. "Understanding learning systems: mathematics teaching and complexity science," Journal for Research in Mathematics Education, 34 no.2 (2003),141.

${ }^{10}$ See Peter Miller. "Swarm Theory," National Geographic, 212 no. 1 (2007) via

http://www7.nationalgeographic.com/ngm/0707/feature5/

${ }^{11}$ Sandpipers' Bread and Breakast, "Historic Harvey Bank Community Pasture Mary's Point Sandpipers" http://sandpipersrest.nb.ca/sandpipers.jpg (accessed October 26, 2007). Image used with the kind permission of Stephen and Patrica Marshall, Sandpipers' Rest Bed \& Breakfast, Harvey Albert County, New Brunswick. ${ }_{12}^{12}$ See Prigogine's distinction between open and closed systems in Doll, 1993, p. 57.
} 
once foreign to the system, are now an integral part of the system. The ecosystem adapted (transformed) itself to environmental circumstances. ${ }^{13}$

Systems that display self-organization, self-maintenance, and the ability to adapt to changing environments may be said to be learning systems "where learning is understood as a process through which a unity becomes capable of more flexible, more creative activity that enables the unity to maintain its fit to its ever evolving context." 14

When a complex adaptive system is portrayed as a learning system (whose components are humans) the move to educational contexts seems quite natural. This application of complexity science and new concept of learning creates new ways of imagining and talking about educational processes.

\section{Complexity science and educational research}

\section{The Edmonton School and the "thesis"}

Among the graduate students in the Department of Secondary Education at the University of Alberta in the 1990s, three in particular became interested in exploring what complexity science might have to add to educational discourses. Although they have worked in several universities across the nation since earning their doctorates, they have continued to work collaboratively on a number of projects and writings. The three educationists are Professors Brent Davis, Elaine Simmt and Dennis Sumara. ${ }^{15}$

I focus here on a paper authored by Davis and Simmt ${ }^{16}$ and elaborate on certain aspects of the paper in a book by Davis and Sumara. ${ }^{17}$ In examining both works, I highlight the provocative idea that classroom collectivities (students and teachers) are learning systems in their own right. Referring to the work of other researchers seeking to connect understandings of learning as a social and as an individual phenomenon, Davis and Simmt remarked:

\footnotetext{
We have made similar observations, which have prompted us to turn to complexity science as a means to re-describe a classroom collective as a learning system. We suspect, that is, that the tendency to see classroom groupings as unities with personalities is not simply a matter of figurative referencing or anthropomorphism. Rather, for us, this tendency reveals a capacity to recognize events of emergence.

In research terms, this move toward understanding the collective as a cognizing agent (as opposed to a collection of cognizing agents) presents some important advantages. ${ }^{18}$
}

Davis, Simmt, and Sumara went beyond the descriptive possibilities of revisioning where learning occurs moving into the pragmatic considerations of how complexity science informs us about the possible formation and transformation of such collective intelligences. They think of this as "the shift from descriptions of learning to recommendations for teaching." 19 Following their lead, I begin with the descriptive by looking at some necessary, but not sufficient, conditions for the emergence of a

\footnotetext{
${ }^{13}$ Brent Davis, Dennis Sumura and Rebecca Luce-Kapler, Engaging minds: Learning and Teaching in a Complex World ( Mawah, NJ: Lawrence Erlbaum Associates, 2000), 63.

${ }^{14}$ Davis and Sumara, 92

${ }^{15}$ Current homepages are http://cust.educ.ubc.ca/faculty/davis.html , http://www.ualberta.ca/ esimmt/ and http://www.cust.educ.ubc.ca/faculty/sumara.html The University of Alberta maintains a site on complexity and education at http://www.complexityandeducation.ualberta.ca/index.htm

${ }_{16}^{16}$ Davis and Simmt.

${ }^{17}$ Davis and Sumara.

18 Davis and Simmt,144

19 Ibid., 144.
} 
class as a learning entity in its own right. Then I follow with some suggestions as to how this emergence might be facilitated.

\section{Conditions for emergence in a classroom}

Davis and Simmt identified "certain necessary but insufficient conditions [that] must be met in order for systems to arise and maintain their fitness within dynamic contexts—-that is, to learn." 20 Of these conditions they choose five that are most germane to their arguments. The conditions are (a) internal diversity, (b) redundancy, (c) decentralized control, (d) organized randomness, and (e) neighbour interactions. When Davis and Sumara revisited this list, they modified it into three complementary pairs: specialization, trans-level learning, and enabling constraints. ${ }^{21}$ Specialization addresses the necessary tension between the need for both diversity and redundancy. Trans-level learning pairs neighbour interactions and decentralized control. This highlights the necessary balance between flexibility and robustness that a viable learning system must maintain. Enabling constraints—a revision of the seemingly oxymoronic "organized randomness"-emphasizes the need for both creative randomness and identity-preserving coherence. ${ }^{22}$ Davis and Sumara explained their restructuring of the list: "Our reason for organizing the discussion around dyads is to foreground that complex emergence happens far-from-equilibrium." 23 Emergence is an interplay of both negative and positive feedback; it is not the absence of tension, but a dynamic balancing of opposites.

Specialization

In terms of a classroom collective (or, in this dawning age of online learning, community of learners and teachers) redundancy ${ }^{24}$ might be thought of as common understandings and language, "duplications and excesses of those aspects that are necessary for complex co-activity." 25 Davis and Simmt noted that redundancy is connected to the collective's health with respect to the strength of its internal coherence and ability to cope with adverse environments. "Redundancy thus plays two key roles. First, it enables interactions among agents. Second, when necessary, it makes it possible for agents to compensate for others' failings." 26 Students have sufficient common background to speak with each other and the class will not cease to make progress because of the absence of any one individual.

Internal diversity is closely linked with a system's creativity or intelligence. The insight that a group's potential for varied response increases with the sum total of the individual capabilities within the group is not unique to complexity science. But complexity science accentuates that such diversity is a sine qua non for a collective intelligence. In a complex system, however, it is not the existence of diverse talents among its agents, but the appropriate interaction of such talents that gives rise to adaptive behaviours that transcend those of the system's individuals. Can the understandings of a class go beyond the potential understanding of any single member within the class? Complexity science argues in the affirmative.

\footnotetext{
20 Ibid., 147.

${ }^{21}$ Davis and Sumara,136.

22 This underscores Bateson's dictum that nothing new can arise without randomness. Cf. Bateson.

${ }^{23}$ Davis and Sumara, 136.

${ }^{24}$ Davis and Sumara note the negative connotations of the current usage of redundant. Redundancy in a (complicated) machine is inefficient, but is necessary in a healthy organism.

${ }^{25}$ Davis and Sumara, 138.

${ }^{26}$ Davis and Simmt, 150.
} 
Diversity in a class determines how well it will respond to the external environment (such as, for example, the curriculum). Redundancy in a class is key to establishing coherence. External flexibility is kept in balance with internal robustness.

Trans-level Learning

The dyad of neighbor interactions and decentralized control can be usefully thought of in terms of network topologies. A network may be thought of as centralized, decentralized, or distributed with structures as represented in figure 1. A centralized network has a central node that connects to all other nodes. The architecture of a computer with a single central processor is an example of such a network. A distributed network is a complete graph where every node is an "equal among equals" and is connected to every other node. A peer-to-peer local area network of personal computers is an example. A decentralized network is, what else, complex. Not all nodes are equal and not all nodes are connected. The iconic decentralized network is the world wide web. ${ }^{27}$

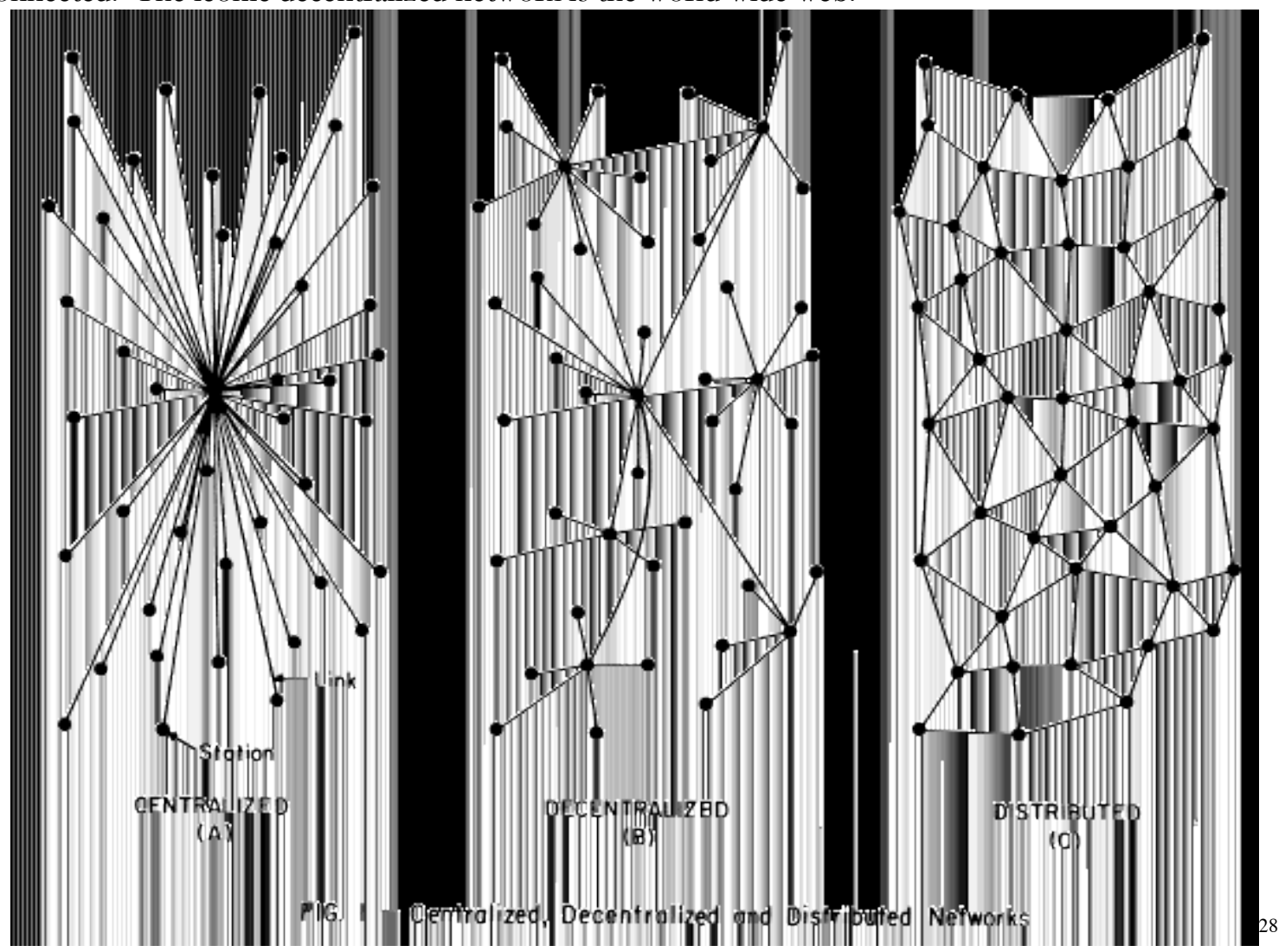

In terms of classroom images, we can think of the teacher-centred classroom as a centralized network and the "free for all" student-centred classroom as a distributed network. The centralized network is very efficient in terms of transmitting knowledge throughout the network, but is vulnerable

\footnotetext{
${ }^{27}$ Decentralized networks have a fractal nature in that they maintain the same complexity of structure at any scale they are observed. That is, an appropriately chosen neighborhood of a decentralized network has the same features as the network as a whole. The roughness of the network does not smooth out when one "zooms in or out". The fractal nature of a decentralized network has implications that are not fully pursued in this current paper.

28 Malcolm Gibb TMA04 P5779889, “The ARPANET, Internet, and TCP/IP”,

http://www.btinternet.com/ sandyloan/Networks.gif (accessed on November 24, 2007).
} 
to external attacks on the central hub and is not particularly good in responding to problems in novel ways. ${ }^{29}$ The distributed network has problems of internal coherence and efficiency of information transfer, although it is robust and flexible in its responses to external challenges. Consistent with the balanced tension of diversity and redundancy, we associate the complex classroom with a decentralized network. Furthermore, we understand that these networks are dynamic with internodal communication occurring across links.

Figure 1 might suggest that the three topologies are distinct and separate. In fact, it might be more accurate to think of the network structure of a complex adaptive system continually morphing from one topology to another under the influence of external and internal demands. In particular, we can easily envisage a class that begins as a teacher-directed enterprise which then moves deliberately into a distributed network of brainstorming and then might coalesce into interacting hubs of small group problem-solving. It is not that complex adaptive systems preclude the centralized and distributed network structures at various times in the lives of the systems, but rather that the decentralized structure is necessary at some point in time if emergent behaviours are to arise.

With respect to neighbor interactions in educational contexts Davis, Simmt and Sumara are quite clear that it is not merely a matter of students communicating. They stated:

...we have come to realize that the neighbors in knowledge-oriented communities are not physical bodies or social groupings. Rather, the neighbors that must interact with one another are ideas, hunches, queries, and other manners of representation. ${ }^{30}$

Group work is not a panacea for facilitating emergence in the classroom. Rather, it is collision of diverse ideas and representations that may lead to a self-organization of the class's knowledge into something that transcends the sum of the students' individual knowledge. Again, we note the dynamic aspect of this picture. It is not the existence of conceptual diversity here, but the interactive "flying about" of ideas in sufficient density that means they do indeed bump into one another. ${ }^{31}$

Consistent with the imagery of ideas bumping into each other is the lack of central organization and control. Davis and Sumara link neighbor interactions and decentralized control as follows.

...one of the first lessons of enabling neighbor interactions is that one must relinquish any desire to control the structure and outcomes of the collective. Consistent with such unities as brains, anthills, cities, and ecosystems, control in a knowledge-producing collective must be understood as decentralized, arising in local activities. ${ }^{32}$

It is the intelligence of the decentralized network that is spotlighted here, not that of individual nodes. But due to the fractal nature of such networks, we have the same complex structure at many levels. If the class collective learns, so do the students (and teachers!) that comprise the class. "Learning, in complexity terms, is always a trans-level phenomenon." 33 In particular, complexity science "compels us to question an assumption that underlies both teacher-centered and learner-

\footnotetext{
${ }^{29}$ The history of artificial intelligence is illustrative. AI researchers reacted to their lack of success with larger and faster central processors. Such systems did not display the adaptive, "intelligent" behavior they sought. Much more success has been achieved with the use of arrays of processors.

${ }^{30}$ Davis and Sumara, 142. See also, Davis and Simmt, 156.

${ }^{31}$ We note that the ideational interactions among neighbours in this example differ dramatically from the local interactions of flocking birds. It is precisely the lack of collisions between nearby birds that is part of the flock's emergent behavior.

${ }^{32}$ Davis and Sumara, 144.

${ }^{33}$ Ibid., 142.
} 
centered arguments - namely, that the locus of learning is the individual. Learning occurs on other levels as well." 34

If we allow that knowledge might be generated and shared throughout collectives, the notion of decentralized control posits as a corollary the notion of shared authority within the classroom. ${ }^{35}$ Davis and Sumara stated, "For us, then, an important element in effective educational and research practices is the capacity to disperse control around matters of intention, interpretation, and appropriateness." And later, "Within complexity thinking, just as learning is distributed among agents and across levels of organization, so is authority." 36

The complex classroom is coming to look less familiar to us as the details unfold. We are conditioned to think of control, power, and authorship of knowledge as situated in individuals or groups of individuals. Final authority for what constitutes suitable truths for a class might be a curriculum, a text, or a teacher. Complexity science invites us to consider the possibility and potential of the collective becoming the arbiter of the correctness and appropriateness of the knowledge produced by the system, rather than a centralized source of authority. A characteristic of emergent learning, after all, is that it should surprise the individuals within the class-and this includes the teacher (or whomever holds the "answers").

Enabling constraints

Enabling constraints ${ }^{37}$ "refers to the structural conditions that help to determine the balance between sources of coherence that allow a collective to maintain a focus of purpose/identity and sources of disruption and randomness that compel the collective to constantly adjust and adapt." 38 Davis and Simmt argued that enabling constraints are proscriptive, rather than prescriptive. ${ }^{39}$ That is, prescription details what must happen; proscription sets boundaries and describes only what must not happen. Enabling constraints seek a via media between the narrowness of prescription and the ambiguity of having no constraints whatsoever. Davis and Sumara identified the critical features of enabling constraints as "(1) sufficient coherence based on a sufficiently constrained domain...and (2) an openness to randomness in order to allow for the emergence of unanticipated possibilities." 40 The complex classroom maintains "a delicate balance between sufficient organization to orient agents' actions and sufficient randomness to allow for varied and flexible response." 41 Between everyone doing the same thing and everyone doing their own thing lies everyone participating in a joint project. ${ }^{42}$

Enabling constraints are situational. Complex systems by their organic natures are in a state of flux. The appropriate enabling constraint for one class at one time is unlikely to be the same for another class at another time. The quality of emergence adds a constant element of surprise and "on the spot" tinkering to the classroom.

It is necessary to note that, true to nature of complex systems, the pairs of conditions discussed above cannot be considered independently. They are all entangled with one another. But, by envisaging a class participating in these tensions, we can develop a sense of the complex adaptive entity

\footnotetext{
${ }^{34}$ Davis and Simmt, 152.

35 The use of the word authority rather than power is deliberate. "Authority" is etymologically related to "author," and it is the authorship of the knowledge produced that is in question here.

${ }^{36}$ Davis and Sumara, 145.

${ }^{37}$ Enabling constraints were called liberating constraint in Davis, Sumara, and Luce-Kapler and organized randomness in Davis and Simmt. The language of complexity science is still stabilizing.

${ }^{38}$ Davis and Sumara, 145.

${ }^{39}$ Davis and Simmt, 154.

${ }^{40}$ Davis and Sumara, 149.

${ }^{41}$ Davis and Simmt, 155.

42 Ibid.
} 
that such a class might constitute. Just as the beehive is more than a collection of bees, we can begin to think of a class as more than a collection of students and teachers.

\section{Occasioning emergence in a classroom}

We put in abeyance for the moment the question of whether or not a class that is a complex adaptive system is a desired educational goal or if it is possible within the current institutional frameworks. Positing that in some instances and in some circumstances the learning that occurs in a classroom exceeds the learning one would expect from the known capabilities of the constituent individuals - that is, "the emergence of conceptual and interpretive possibilities that might not have been considered by any member of the group" ${ }^{43}$-we can ask how we might facilitate such occurrences. Emergence is a bottom-up phenomenon that occurs internally within a complex adaptive system; it is not something that can be imposed upon a system by external controls. But perhaps the conditions that give rise to emergence can be nurtured, facilitated, or, in the language of Davis, Simmt, and Sumara, "occasioned".

Davis, Simmt and Sumara did not give replicable methods for ensuring classes will become complex adaptive systems. Instead, they pointed out that the nature of complexity works against guaranteed success in general. They offered illustrations rather than exemplars. Davis and Simmt declared:

The intention, then, is not to suggest some sort of reliable route to complex collective mathematical engagements. Rather, we present and interpret an instance in which deliberate and conscious efforts to structure a learning activity around the principles presented above seemed to occasion some provocative possibilities in a mathematics classroom. ${ }^{44}$

Davis and Sumara ${ }^{45}$ elaborated on this by writing, "Complexity cannot be managed or scripted into existence. Yet it can sometimes be occasioned." On a more positive note, they declared, "we are asserting that complexity thinking has evolved into a pragmatics of transformation-this is a framework that offers explicit advice on how to work with, occasion, and affect complexity unities." 46

The illustrations that Davis, Sumara and Simmt offer as examples of communities of learners self-organizing into complex adaptive systems are interesting in their diversity. Davis and Simmt discussed a group of in-service teachers who came back to university to take a mathematics course. These teacher-students formed study groups and as a collective coped with the externally imposed challenges of the geometry course. A second illustration came from a seventh grade mathematics class in which working with a particular concept benefited from conceptual blending within the collective. A third illustration is reported in Davis and Sumara and involves a group of practicing teachers. Davis, Simmt and Sumara worked with this group over a number of years and documented an incident of collective understanding that occurred in the fourth year. In interpreting all three illustrations, there was a focus "on group collectivity and the consequences of such a focus for individual understanding and broader social contexts." 47

The example of the seventh grade classroom suggests some of the "explicit advice" to those who would occasion emergent understandings in the class. There is a task that acts as an enabling constraint. It must be sufficiently focused to encourage coherence among student responses and simultaneously sufficiently open-ended to allow serendipitous randomness into the conversation. In this case, students were paired off (by the teacher) to answer a specific question (focused) and explain

\footnotetext{
${ }^{43}$ Davis and Simmt, 157.

44 Ibid., 157

${ }^{45}$ Davis and Sumara, 152.

${ }^{46}$ Davis and Sumara, 130.

47 Ibid., 152.
} 
on a poster how they arrived at their answers (potential randomness). The students paid close attention to each other's presentations (neighbour interactions) and discussed the presentations with each other. During these discussions a "reblending" of concepts (which were a consequence of internal diversity) resulted in emergent understandings. Such understandings emerged bottom-up; an external final authority did not impose them. The teacher was responsible for attempting to establish the necessary redundancies in the classroom of common understandings, expectations and "collective rules of engagement." 48 These efforts occurred over a considerable amount of time prior to the classes described. The teacher was also responsible for the dispersion of authority throughout the class whenever possible. In particular, the teacher sought to allow conversations to reach whatever conclusions they might veer towards (within the constraints of some loosely defined correctness) without bending them to some predetermined path. To this extent, authority and authorship were dispersed throughout the collective.

What the teacher (or, more accurately in this case, teacher-researcher) brought to this classroom was an understanding of the principles for occasioning emergence, an attentiveness to the dynamics of the collective (as well as to the individuals), and an attitude that complexity in the classroom is to be valued.

Relating their thesis to a more familiar classroom experience, Davis and Simmt wrote:

Across these projects, a consistent and somewhat resilient theme has arisen. As conditions for complex emergence are described, illustrations provided, and engagements prompted, inevitably discussions turn to the phenomenon of the teachable moment - a cohering of many bodies in an instance of shared purpose and insight.

...we offer that the phenomenon of the teachable moment can be the rule of ...classrooms, not the exception. The key is a willingness to understand the classroom community as an adaptive, self-organizing, complex unity. ${ }^{49}$

The authors remind us that the conditions listed above are necessary, but not sufficient. A classroom may have redundancy and diversity, there may be a high density of diverse ideas bumping into each other, proscriptive enabling constraints may be the task at hand, and control and authority may be distributed throughout the class, and yet the class will fail to self-organize into a learning system. Complexity is not guaranteed. On the other hand, "a neglect of such conditions will provide a reasonable assurance that collective activity will never exceed the collection of individual insights." 50 If occasioning emergence in the learning collective is so difficult and uncertain, why should we be interested in doing so? The last section in this paper begins to address this question.

\section{Possibilities and challenges of thinking of a class as a learning system}

Education is a transphenomenal, transdisciplinary, and interdiscursive enterprise. Research into education necessarily reflects this. ${ }^{51}$ Because of the breadth of human activity encompassed in educational research, there is an aspect of the Tower of Babel in looking at the field as a whole. Much effort has been put into articulating the distinctions among the different emphases and perspectives adopted; equal effort has been expended on showing how they are alike. Complexity science suggests we put aside the questions of differences and similarities and focus on the question of the level of complex organization at which a particular theory is most fruitful. The researcher's question becomes

\footnotetext{
${ }^{48}$ Davis and Simmt, 161.

${ }^{49}$ Ibid., 164.

50 Ibid., 164.

51 One need only peruse the directory of Special Interests Groups of the American Educational Research Association at http://www.aera.net/Default.aspx?menu id=26\&id=274 to verify that educational research reaches across phenomena, disciplines, and discourses.
} 
not "where does learning occur?" but "what level of emergence is the current focus?" Understanding that learning is not confined to any one level of nested complex unities, Davis and Sumara claimed:

Complexity thinking is not a metadiscourse that seeks to offer totalized explanations, but an umbrella notion that enables researchers to note profound similarities across a diversity of phenomena. As such, its immediate contribution to educational research is in the provision of a means to address and foreground the deep similarities of some heretofore disparate—and, at times, seemingly oppositional—-theories and research foci. ${ }^{52}$

As a particular example of the bridging capabilities of complexity science in educational discourse, we can look at the constructivist theories of personal meaning making, the constructionist perspectives on the role of social context in learning, and the role of power structures in education discussed in critical constructivism. Davis and Simmt noted that, "For us, the main attraction of complexity science is that it provides means of reading across the concerns and contributions of radical, social, and critical constructivist discourses." 53 Personal subjectivity, intersubjectivity, and the cultural imperatives of power become nested levels of the single complex human activity of education rather than separate approaches.

The strength of complexity science in "reading across" the many aspects of educational research may be a significant weakness as well. Complexity science and its nested levels of learning systems may be too successful in accommodating the many voices of educational research. By being so open and encompassing, complexity science risks saying nothing new about education. Educational researchers adopting complexity science perspectives must look not only at how complexity science brings together previously developed theories, but also at what new insights it might generate.

A second challenge for the value of complexity science in educational research is whether or not the research can move beyond the descriptive to the practical. This is a challenge for many of the theoretical frames used in educational research. How does the characterization of learning generated by a particular investigation translate into advice about teaching? Davis and Sumara claimed that the challenge faced by many perspectives in educational research in offering practical advice to teachers is the specificity of their interests. Educational practices, however, involve many simultaneous and diverse activities. $^{54}$ The educator must be attentive to many issues and phenomena. To the extent that complexity science is successful in encompassing the wide range of activities and concerns involved in educational ventures, it is well suited to offering practical advice about transforming learning systems.

The very real concern is whether or not this advice leads to outcomes compatible with or desired by modern schools. An account of the classroom informed by complexity science and the encouragement of emergent behavior do not, however, fit that well with existing conceptualizations of schooling. Prescription rather than proscription seems to be the rule of the day. Nor is complexity science, with its bracketing of control and predictability, compatible with many contemporary models of school administration. Evaluation and assessment schemes favoured by administrators, parents, and even students may not be sanguine about a constantly far-from-equilibrium classroom. Students may not tolerate for long periods of time the dissonance, ambiguity, and unease that are part of the bottomup emergent process. Is the complex classroom an actual educational goal sought by many of the stakeholders in schooling?

Another aspect of the work done by Davis, Simmt, and Sumara is the admission that the occurrence of emergent phenomena in the classrooms is episodic. Classrooms do not naturally stay in far-from-equilibrium states for prolonged periods. This does not mean that we have to abandon the concept of the classroom as a collective learning system. Rather, we can recognize the organic nature

\footnotetext{
52 Davis and Sumara, 127.

53 Ibid., 163-164.

${ }^{54}$ Davis and Sumara, 130.
} 
of such a system in which there are periods of intense activity interspersed with periods of calm. A quiescent organism is not necessarily unintelligent. We need to ask what advice complexity science gives not only to the teacher seeking emergent behaviours, but also to the teacher working with a class whose complex nature currently lies below the surface.

Teachers, in particular, may find it difficult in an age of "methods" courses and "best practices" to engage with a view of teaching informed by complexity science. This is not helped by the vagueness of the advice given to the would-be complexivist educator. Davis admitted that, "Unfortunately, a vocabulary to frame complexivist teaching has yet to emerge." 55 Such teaching is currently discussed more readily in terms of what it isn't than in specifics of what should be done. The pragmatic advice given to teachers is that teaching is not a matter of management, rather, "a teaching informed by complexity science might be described as a sort of improvising in the jazz music sense of engaging attentively and responsively with others in a collective project." 56 It may be that the beginning teacher would be more adverse to a perceived lack of structure in such teaching than established teachers. Complexity science does seem to offer language and concepts to match the sensibilities and intuitions of practicing teachers..$^{57}$

Another issue surrounding the occasioning of emergent behaviours in classroom collectives involves ethical dimensions. Complexity science addresses the questions of what is and what could be, but begs the question of what should be. Davis characterizes this as a concern for practical know-how rather than ethical know-how. ${ }^{58}$ For the classroom teacher, the account of collective learning offers advice on increasing the frequency of that sought-after teachable moment. But we need to ask who values this moment and why. Decentralized control and dispersion of authority are necessary conditions for emergence, but how does this reapportionment of power actually impact on the individual agents of the collective? Complexity science situates critical theory in its nested levels of complexity structures, but does it attempt to answer the questions asked by such discourses?59

Having stated caveats, I can still unequivocally assert that insertion of complexity science into educational discourses has enriched and enlivened the discussions about teaching and learning. In particular, the concept of the class as a complex adaptive system, a learning entity, offers an intriguing and generative metaphor. Researchers can converse with each other across disciplines and discursive domains. Educators are challenged to reconsider their roles in the classroom and what might occur there as complexivist accounts of learning and teaching interrogate and disrupt accounts that regard learning and teaching as possibly complicated, but not complex. Terms such as "classroom management," "efficiency," "best practices," and "achieved curricula" become problematic, or at least problematized. Futurists can look to complexivist accounts of education in guiding the design of their distance/online/virtual courses. How does one encourage decentralized networks in such courses?

Can curriculum theorists discuss a curriculum that is truly attentive to the possibilities of collective intelligences and the transdisciplinary nature of knowledge? Researcher, teacher, and reflective student may all find it worthwhile to play with the ideas and to discuss them in their own (possibly emergent) communities of learning.

\section{Acknowledgments}

\footnotetext{
${ }^{55}$ Davis, 170.

56 Ibid., 170.

${ }^{57}$ When parts of this paper were presented at the $6^{\text {th }}$ Annual Education With/Out Borders conference in 2007 one participant said that complexity science gave her the language to talk about what she was already doing. ${ }^{58}$ Davis, $173-174$.

${ }^{59}$ Davis argued that, true to its nature, complexity science is not in itself a completed project. The discourses of complexity science bifurcate into ecological discourses at exactly the point of ethical know-how.
} 
Parts of this paper were presented at the Sixth Annual Education With/Out Borders symposium held in Port Moody, October 26 to $28,2007$.

We acknowledge the kind permission of Stephen and Patrica Marshall, Sandpipers' Rest Bed \& Breakfast, Harvey Albert County, New Brunswick for the use of the "Historic Harvey Bank Community Pasture Mary's Point Sandpipers" image.

\section{Bibliography}

AERA, "Special Interest Groups", AERA, http://www.aera.net/Default.aspx?menu id=26\&id=274

Bateson, Gregory. Mind and nature: a necessary unity. Cresskill, NJ: Hampton Press, 1979.

Capra, Fritjof. The web of life: A new scientific understanding of living systems. New York: Doubleday, 1996.

Davis, Brent. Inventions of teaching: A genealogy. Mawah, NJ: Lawrence Erlbaum Associates, 2004.

Davis, Brent and Elaine Simmt "Understanding learning systems: mathematics teaching and complexity science." Journal for Research in Mathematics Education. 34 no. 2 (2003): 137-167.

Davis, Brent and Dennis Sumara. Complexity and education: Inquiries into learning, teaching, and research. Mawah, NJ: Lawrence Erlbaum Associates, 2006.

Davis, Brent, Dennis Sumara, and Rebecca Luce-Kapler. Engaging minds: Learning and Teacbing in a Complex World. Mawah, NJ: Lawrence Erlbaum Associates, 2000.

Doll, William. A post-modern perspective on curriculum. New York: Teachers College, 1993.

Malcolm Gibb TMA04 P5779889, "The ARPANET, Internet, and TCP/IP”, http://www.btinternet.com/ sandyloan/Networks.gif

Miller, Peter. "Swarm Theory.” National Geographic 212 no. 3 (March 2007): 126-47.

Sandpipers' Bed and Breakfast, "Historic Harvey Bank Community Pasture Mary's Point Sandpipers", http://sandpipersrest.nb.ca/sandpipers.jpg

Waldrop, M. Mitchell. Complexity: The Emerging Science of Order and Chaos. (New York: Simon \& Schuster, 1992).

\section{About the Author}

Craig Newell was a Ph.D. student in the Mathematics Education cohort. 